\title{
A proteomic analysis of the effect of radiation therapy on wound healing in women reconstructed with the TRAM flap
}

\author{
Bekka O. Christensen $^{1,2}$, Jens Overgaard ${ }^{2}$, Henrik Vorum ${ }^{4}$, Bent Honore ${ }^{3}$, Tine E. Damsgaard ${ }^{1}$ \\ ${ }_{1}^{1}$ Department of Plastic Surgery, Aarhus University Hospital, Aarhus, Denmark \\ ${ }^{2}$ Department of Experimental Clinical Oncology, Aarhus University Hospital, Aarhus, Denmark, \\ ${ }^{3}$ Department of Medical Biochemistry, University of Aarhus, Aarhus, Denmark \\ ${ }^{4}$ Department of Ophthalmology, Aalborg University Hospital, Aalborg, Denmark \\ Email: bekka@oncology.dk
}

Received 10 July 2013; revised 20 September 2013; accepted 13 October 2013

Copyright (C) 2013 Bekka O. Christensen et al. This is an open access article distributed under the Creative Commons Attribution License, which permits unrestricted use, distribution, and reproduction in any medium, provided the original work is properly cited.

\section{ABSTRACT}

The incidence of breast cancer is still increasing, and with improved cancer treatment, more women live longer with the side effects of their treatment. The response of normal tissue to radiation continues for years after the treatment is completed. The influence of radiotherapy on the outcome of breast reconstructtive surgery remains unpredictable. The combination of two surgical sites of which one is previously irradiated, is rarely encountered in humans and thus compiles a unique opportunity to study the implications of irradiation followed by surgery. The aim of this study was to examine the long-term effect of radiation therapy on the proteins expressed in the wound tissue after a breast reconstruction. Ten patients were included in the study, all treated with radiotherapy after a mastectomy and breast reconstruction with a contralateral pedicled TRAM flap. Expanded polytetrafluoretylene polymer tubes were implanted for 10 days, subcutaneously, below the inframammary fold and below the donor site. The protein from the newly synthesized granulation tissue in the tubes was extracted and analyzed for differences in protein expression with 2D gel electrophoresis and mass spectrometry. A total of 676 proteins were detected; of these, 4 proteins changed significantly and were successfully identified. TPM4 and APOA4 from the radiation treated tissue were shown to be significantly decreased, whereas IGKC and VDAC1 were found to be significantly increased. The proteomic technique combined with the ePTFE tube wound model can elucidate some of the molecular alterations in the wound healing induced by radiation therapy. The protein modifications of TPM4, APOA4, IGKC and
VDAC1 may influence the cell proliferation, apoptosis and the inflammation of the tissue repair process.

Keywords: TRAM Flap; Radiation Therapy;

Reconstructive Surgery; Human; Proteomics; TPM; VDAC; APOA4

\section{INTRODUCTION}

The healing process is the basis of all surgeries. Therefore, it is crucial to gain knowledge of the biology of the tissue repair process and the factors influencing it: how to optimize the healing process, diminish the postoperative complications.

The incidence of breast cancer is still increasing, and with improved cancer treatment, more women live longer with the side-effects of their cancer treatment. The destruction or damage of healthy tissue/cells outside the tumour has both acute and long-term side-effects. Late sequelae from radiation therapy (RT) include skin atrophy, pigmentation changes, soft tissue fibrosis and micro-vascular damage [1].

The combination of RT and breast reconstruction has generated significant discussion. Several studies have retrospectively evaluated aesthetic outcome and complications after mastectomy, radiation therapy and subsequent breast reconstruction. The overall conclusion is that radiation therapy increases morbidity and decreases the aesthetic outcome; patients will contract more complications and an inferior outcome is unpredictable [2-6].

In 1982, Hartrampf et al. introduced the pedicled transverse abdominal muscle flap (TRAM flap) for reconstruction of the breast. Variations of this versatile flap 
are common methods for autologous breast reconstructtion, and often recommended for women previously treated with radiation therapy, as it transposes non radiated tissue into the irradiated area.

Radiation therapy is confined to the irradiated tissue volume and therefore, enables examination of both irradiated and non irradiated tissue from the same individual. The combination of two surgical sites, one of which is previously irradiated, is rarely encountered in humans. Thus, the TRAM flap procedure compiles a unique opportunity to study the implications of irradiation followed by surgery.

Previous studies have reported impaired wound healing and radiation induced tissue changes [1,7-9]. The pathogenesis of the radiation induced tissue alterations are complex, involving a cascade of molecular and cellular events. The time span in which such alterations occur is uncertain.

The proteome is the entire complement of proteins, including modifications that vary with time and requirements. It is well known that mRNA is not always translated into protein; the amount of protein produced for a given amount of mRNA depends on both the gene. It is transcribed from the current physiological state of the cell. These (post-translational) modifications affect the function of the proteins, and are therefore important in the understanding of the patophysiological process causing the changes in the tissue repair process. Proteo- mic analysis can determine the expression levels of pro- teins, including the modifications [10].

Proteomic analysis, based on two dimensional electrophoresis (2-DE), has primarily been conducted to study carcinogenesis, signal pathway profiling, and molecular markers [11]. To our knowledge, no study has used proteomics to examine the changes in the tissue repair response, induced by previous radiation therapy, in newly synthesized granulation tissue from humans. Most studies working with radiation therapy and proteins use techniques involving specific protein antibodies. They require a beforehand knowledge of which proteins are influenced by RT. Other studies focus on cell cultures or wound fluids $[12,13]$.

The expanded polytetrafluorethylene polymer tube (ePTFE tube) is a model for studying wound healing in humans [14].

The proteomic analysis provides the possibility of examining proteins without a priori knowledge of which protein properties are altered by radiation therapy and subsequent surgery.

\section{MATERIALS AND METHODS}

\subsection{Patient}

After a modified radical mastectomy for breast cancer, ten women were consecutively included in the study. The women were reconstructed with a contralateral pedicled TRAM flap at the Department of Plastic Surgery, Aarhus University Hospital, Denmark. All had been treated with radiation therapy according to the national guidelines from the Danish Breast Cancer Cooperative Group [15]. Data were obtained from personal communication, physical examination and charts including information regarding BMI (body mass index), tobacco smoking and adjuvant therapy.

\subsection{Surgery}

The TRAM flap was harvested with a horizontal ellipse of tissue, incorporating the full width and a variable length of the rectus abdominis muscle. The musculocutaneous flap was tensionlessly transposed into the recreated mastectomy defect, supplied by the superior epigastric vessels. The transposed tissue was partly de-epithelized and shaped into a new breast mound. Supra umbilical fascial sheath defects were closed primarily and infraubillical fascial defects were reconstructed using a 15 $\times 15 \mathrm{~cm}$ on-lay polypropylene mesh. The umbilicus was brought out through a central opening in the midline of the abdominal flap and sutured in place. Closure was performed using a layered closure of Scarpa's fascia, subcutaneous tissue and skin.

\subsection{The ePTFE Tube}

The ePTFE tubes (International Polymer Enginering, Tempe, Arizona, USA.) have a $0.12 \mathrm{~cm}$ inner diameter, a $0.25 \mathrm{~cm}$ outer diameter and a pore size of $90-120 \mu \mathrm{m}$. The $9 \mathrm{~cm}$ ePTFE tube was threaded on a 3-0 non-absorbable nylon suture and sterilized before implantation.

The ePTFE tubes were implanted during general anesthesia, in the subcutaneous tissue at the intrammamary fold and at the donor site, using the Seldinger technique. Approximately $1 \mathrm{~cm}$ of the ePTFE tube was left protrudeing outside the skin at the lateral perforation. The ePTFE tube was sutured to the skin with a single nylon 4-0 suture and covered with Tegaderm $\AA$. The ePTFE tubes were removed on postoperative day $10-12$. The external part of the ePTFE tube was discarded and the former subcutaneous parts were immediately divided and snap frozen in liquid nitrogen and stored at $-140{ }^{\circ} \mathrm{C}$.

\subsection{Proteomic Analysis}

The ePTFE tubes were homogenized in lysis buffer and the supernatants were removed. Two-dimensional gel electrophoresis, image analysis and identification of differentially expressed protein spots by mass spectrometry were essentially performed as previously described [16].

The dry and transparent gels were scanned in the transmissive mode on a GS-710 Imaging Densitometer 
from Bio-Rad (Hercules, CA, USA) using the Quantity One software package. Gel images were exported as 16-bit gray scale TIFF files that were imported into the PDQuest 8.0 2D Analysis Software (Bio-Rad). After background subtraction, the protein spots were automatically defined and quantified. Spot intensities were expressed as optical densities (OD) and were normalized against the total density in the gel image. One of the gels used in the analysis comparison was selected as a reference gel to which the other gels used in the analysis was aligned and matched using landmarks, as described in the manual. In the reference gel each spot (feature) was assigned a number. The quality of the match made by the computer was critically evaluated in each case, and necessary editions and corrections were done manually. Initially, spots were selected for analysis that contained an average relative intensity in the RT treated tissue that differed by more than a factor 2 from the not treated wound tissue. The significance of the differences was calculated using the Student's t-test.

Searches were performed in the SwissProt database release 56.0 or 2012-07. Searches were performed with a peptide mass tolerance of 20 or $50 \mathrm{ppm}$, a fragment mass tolerance of $0.05 \mathrm{Da}$, max missed cleavages of 1 or 2 and Carbamidomethyl (C) as fixed modification.

\section{ETHICS}

The study followed the Helsinki Declaration and was approved by the Danish Regional Committee on Biomedical Research Ethics, M-20070039. All patients gave their written informed consent.

\section{RESULTS}

The mean BMI was 25.4 and the mean age 57.2 years. Seven women were non smokers and 3 reported to have stopped a minimum of 4 weeks prior to surgery (Table 1).

Nine women participated in a follow-up visit. Seven (7/9) of the women had a good overall result of the breast reconstruction when assessed objectively. Three of the 10 women had flap necrosis, 2 required minor surgical revision, one lost part of the reconstruction. The two women with objectively inferior results also had necrosis of the flap and small wound defects at the donor sites.

10 gels from the radiation treated tissue and 10 gels from non radiated tissue were analyzed; representative gels are presented in Figures 1(a) and (b). The overall protein expression profiles were very similar. The spots were distributed throughout the gels, ranging from $\mathrm{p} I 3$ to 10 and with $M \mathrm{r}$ between $10-160 \mathrm{kDa}$.

A total of 676 silver stained spots common for all gels were detected, ten proteins were selected that were up-or down-regulated in RT treated tissue compared to not RT treated tissue from the same individual (Figures 1(a) and (b)).

These 10 proteins were excised from the gels and 6 were identified (Table 2).

Tropomyosin alpha-4 (TPM4) and Apolipoprotein A-IV (APOA4) from the RT treated tissue were signifycantly decreased, whereas Ig kappa chain C (IGKC) and Voltage-dependent anion-selective channel protein 1 (VDAC1) were significantly increased. 5 excised spots were not identified due to lack of protein and the spots containing albumin were not included.

Table 1. Patient demographic.

\begin{tabular}{|c|c|c|c|c|c|c|}
\hline Patient & Age (years) & BMI & $\begin{array}{l}\text { Time from RT to } \\
\text { reconstruction (years) }\end{array}$ & & & \\
\hline 290 & 60 & 26.26 & 1.82 & TNM stage & Systemic treatment & Total Dose \\
\hline 296 & 53 & 24.34 & 2.87 & & & (Gy/fractions) \\
\hline 309 & 54 & 26.54 & 1.08 & T1N1N0 & $\mathrm{CH}$ & $48 / 24$ \\
\hline 351 & 45 & 28.09 & 7.13 & T1N1M0 & $\mathrm{C}$ & $48 / 24$ \\
\hline 362 & 64 & 26.61 & 1.44 & T3N1Mx & $\mathrm{CH}$ & $48 / 24$ \\
\hline 367 & 56 & 26.99 & 4.07 & $\mathrm{~T} 2 \mathrm{~N} 1 \mathrm{M} 0$ & $\mathrm{H}$ & $48 / 24$ \\
\hline 372 & 42 & 23.51 & 10.54 & TisN0M0 & & $48 / 24$ \\
\hline 412 & 52 & 22.23 & 3.34 & $\mathrm{~T} 2 \mathrm{~N} 2 \mathrm{bM} 0$ & $\mathrm{CH}$ & $48 / 24$ \\
\hline 494 & 77 & 21.05 & 1.49 & T1aN0M0 & & $48 / 24$ \\
\hline 708 & 65 & 28.69 & 4.41 & $\mathrm{~T} 2 \mathrm{~N} 1 \mathrm{M} 0$ & $\mathrm{CH}$ & $48 / 24$ \\
\hline $\mathrm{H}=$ hormone therapy & & & & T3N2M0 & $\mathrm{CH}$ & $48 / 24$ \\
\hline $\mathrm{C}=$ chemo therapy & & & & $\mathrm{T} 2 \mathrm{~N} 2 \mathrm{M} 0$ & $\mathrm{CH}$ & $48 / 24$ \\
\hline
\end{tabular}




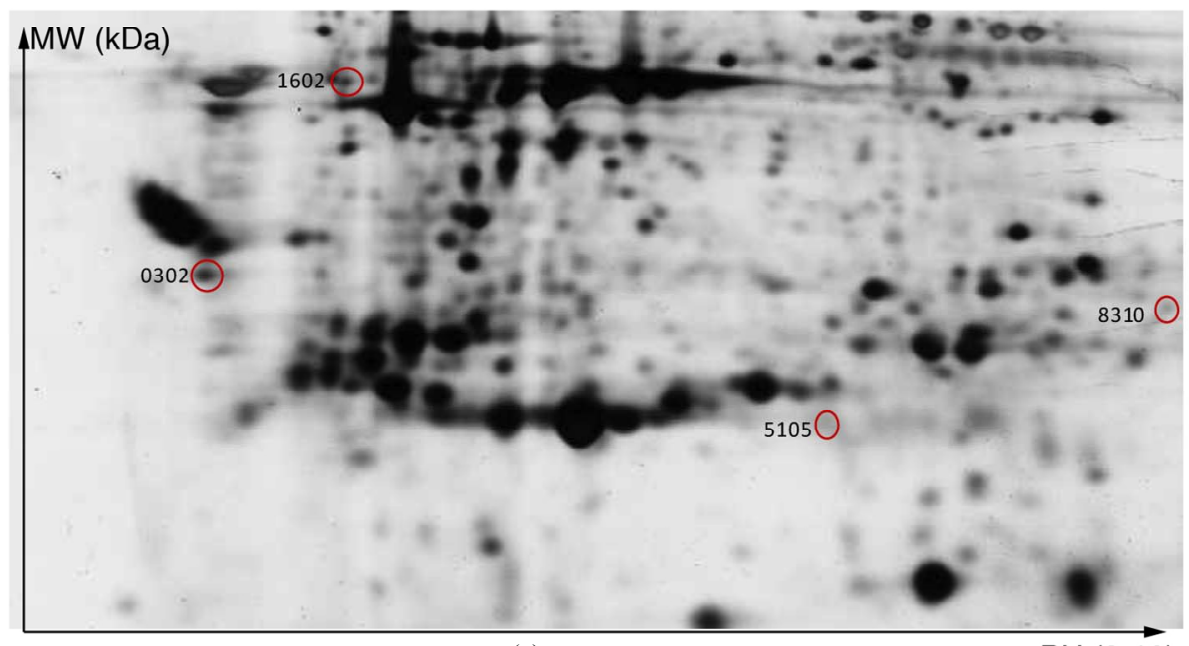

(a)

$\mathrm{PH}(3-10)$

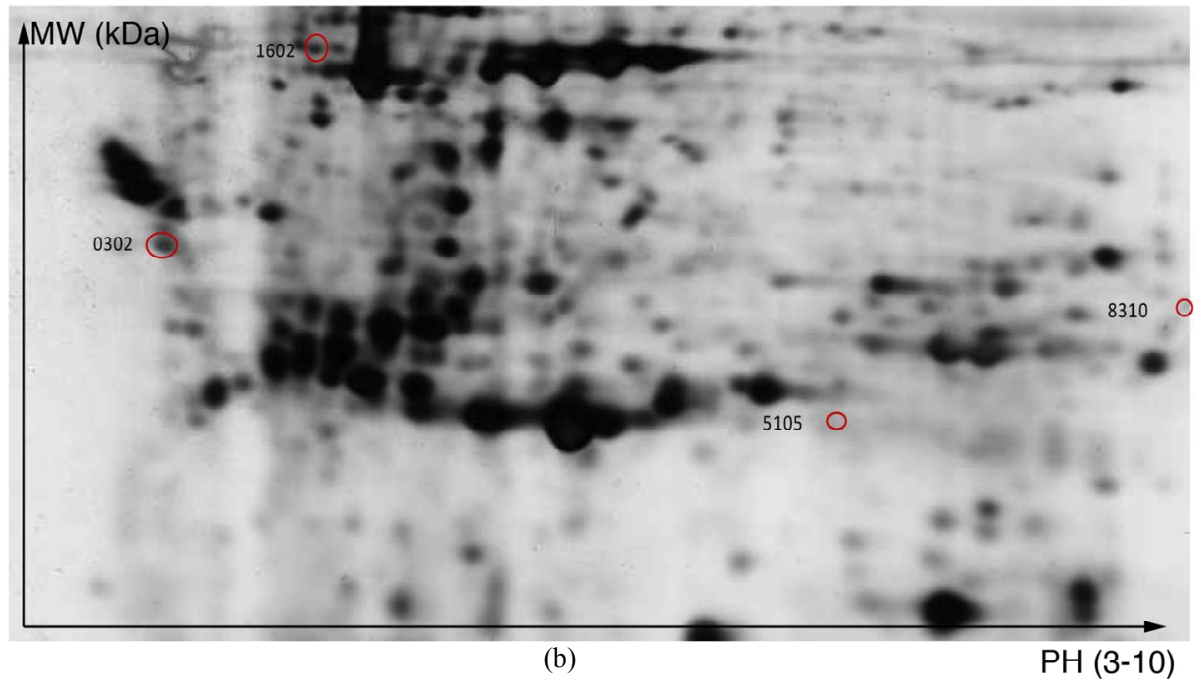

Figure 1. (a) Proteins expressed in tissue collected from below the donor site (no irradiation) by means of 2-Dimensional Electrophoresis. (b) Proteins expressed in tissue collected from below the reconstructed breast (irradiated tissue, by means of 2-Dimensional Electrophoresis.

\section{DISCUSSION}

The expanded polytetrafluorethylene polymer tube (ePTFE tube) wound model was combined with proteomic analysis of the long-term changes in tissue repair after breast reconstruction with a contralateral pedicled TRAM flap in previously irradiated tissue. TPM4, APOA4, IGKC and VDAC1 were identified as differenttially expressed in irradiated tissue. In agreement with our results, Menard et al. concluded that the composition of proteins in tissue changes with radiation exposure [11].

The identification of spot 5105 as both IGKC and albumin introduces the possibility of either one of the proteins expressions being altered, or both the proteins expression that were altered. The protein IGKC forms part of the immune response of the tissues.

TPMs are present in virtually all eukaryotic cells, where they bind actin filaments and stabilize their cell structure. Changes in the expression of TPMs are commonly found in malignantly transformed cells [17]. In humans, tropomyosins are a cytoskeletal family of proteins that range in size from 35 to $45 \mathrm{kDa}$, encoded by TPM1, TPM2, TPM3 and TPM4 genes.

Isoforms of tropomyosin are important determinants of actin cytoskeletal functions such as intracellular vesicle movement, cell migration, cytokinesis, cell proliferation and apoptosis.

Backovic et al. found that the expression of TPM4 protein was significantly correlated with the presence of lymph node metastasis and the clinical stage in breast cancer patients. Their results demonstrated that over expression of TPM4 in breast cancer cells is related to metastatic behavior [17]. Da-Qiang Li et al. used proteomics to analyze tumors of the breast and found that 
Table 2. Identified proteins.

\begin{tabular}{|c|c|c|c|c|}
\hline Protein spot no. & Identity & $\begin{array}{l}\text { SWISS-PROT (primary } \\
\text { accession number) }\end{array}$ & Gene & Functional association \\
\hline 0302 & Tropomyosin alpha-4 chain & P67936 & TPM4 & $\begin{array}{l}\text { Actin binding and cell movement. } \\
\text { Stabilizing of the cytoskeleton }\end{array}$ \\
\hline 1602 & Apolipoprotein A-IV & P06727 & APOA4 & $\begin{array}{l}\text { Lipidtransport Antioxidant activity } \\
\text { Inflammation }\end{array}$ \\
\hline 4806 & Serum albumin & & ALBU & \\
\hline 5105 & Serum albunin & & ALBU & \\
\hline 5105 & Ig kappa chain $\mathrm{C}$ region & P06727 & IGKC & $\begin{array}{l}\text { Immune response antigen } \\
\text { and proteinbinding }\end{array}$ \\
\hline 8310 & $\begin{array}{l}\text { Voltage-dependent } \\
\text { anion-selective channel protein } 1\end{array}$ & P21796 & VDAC1 & Apoptosis Ion transport \\
\hline 1402 & Not identified & & & \\
\hline 3705 & Not identified & & & \\
\hline 5606 & Not identified & & & \\
\hline 6006 & Not identified & & & \\
\hline 7003 & Not identified & & & \\
\hline
\end{tabular}

differently expressed TPM4 was associated to lymph node metastasis and clinical stage [18].

Several molecules associated with neoplastic growth are also nonspecific participants in the transient type of benign proliferation seen in the normal wound healing response. The decrease in TPM4, determined in our study, is possibly part of the reason why healing after RT treatment and surgery is sluggish and can result in a suboptimal outcome. The normal increase in TPM4 does not seem to occur or is delayed.

The voltage-dependent anion channel (VDAC) was first identified in 1976. The VDAC proteins consist of 3 isoforms, VDAC1, VDAC2 and VDAC3, all located on the outer mitochondrial membrane. VDAC forms the main interface between the mitochondrial and the cellular metabolisms; it regulates the energy balance of the mitochondria and the entire cell.

The mitochondria also have an important role in cell signaling events, inter-organelle communication, aging, many diseases, cell proliferation and cell death. The mitochondria function as a center of apoptotic regulation. VDAC has an important function in the regulation of mitochondria-mediated apoptosis, and over expression induces apoptotic cell death. The underlying mechanism is unknown [19]. In our study VDAC1 was identified and significantly increased, which possibly causes premature cell death. Corresponding to our results Voehringer et al used DNA microarray in a B cell Lymphoma model and reported that up-regulation of VDAC was induced by RT [20].

The reduced level of APOA4 protein measured in RT tissue could indicate inflammation of the wound which would be in agreement with Ebrini et al., who found that reduced serum APOA4 expression in arthritis mouse was an indicator of inflammation [21]. There exist only a few non human studies focusing on the connection between APOA4 and inflammation.

No growth factors or cytokines were detected in the current studies perhaps because their high molecular weight and solubility excluded them from the initial isolates. Proteins bound to membranes or with extreme acidic/basic properties that are highly hydrophobic or outside the 10-200kDa interval are not easily identified using 2D-PAGE. Likewise, protein samples can be difficult to prepare, and if the sample has large albumin content, it can cloud smaller proteins.

All the women were previously treated with RT and two had a suboptimal result of their breast reconstructtion.

In conclusion, the understanding of the molecular mechanisms involved in healing after treatment with RT followed by surgery would be expanded with the possibility of appropriate samples and models for further investigation. The present paper contributes with new knowledge of the altered protein properties in previously radiation treated healing tissue. The unique situation of two surgical wounds, of which one was previously irradiated, and the proteomic technique combined with the ePTFE tube wound model, can help elucidate part of the molecular changes in radiation treated tissue. The changes in expression levels of TPM4, APOA4, IGKC and VDAC1 may influence the cell proliferation, apoptosis and inflammation in the wound healing process after reconstructive breast surgery with the pedicled TRAM flap.

\section{ACKNOWLEDGEMENTS}

The authors would like to thank the following for their financial sup- 
nport. None of the foundations had any involvement in the study.

The study was financially funded by the Faculty of Health Sciences, Aarhus University, "Snedkermester Sophus Jacobsen og hustru Astrid Jacobsens Fond", The A. P. Møller Foundation for the advancement of medical Science and The Danish Cancer Society.

\section{REFERENCES}

[1] Dormand, E.L., Banwell, P.E. and Goodacre, T.E. (2005) Radiotherapy and wound healing. International Wound Journal, 2, 112-127.

http://dx.doi.org/10.1111/j.1742-4801.2005.00079.x

[2] Christensen, B., Overgaard, J., Kettner, L.O. and Damsgaard, T.E. (2013) Long-term evaluation of postmastectomy breast reconstruction with the TRAM flap. Journal of Plastic Surgery and Hand Surgery.

[3] Bristol, S.G., Lennox, P.A. and Clugston, P.A. (2006) A comparison of ipsilateral pedicled TRAM flap with and without previous irradiation. Annals of Plastic Surgery, 56, 589-592.

http://dx.doi.org/10.1097/01.sap.0000205057.23543.48

[4] Spear, S.L., Ducic, I., Low, M. and Cuoco F. (2005) The effect of radiation on pedicled TRAM flap breast reconstruction: Outcomes and implications. Plastic and Reconstractive Surgery, 115, 84-95.

[5] Carlson, G.W., Page, A.L., Peters, K., Ashinoff, R., Schaefer, T. and Losken, A. (2008) Effects of radiation therapy on pedicled transverse rectus abdominis myocutaneous flap breast reconstruction. Annals of Plastic Surgery May, 60, 568-572. http://dx.doi.org/10.1097/SAP.0b013e31815b6ced

[6] Williams, J.K., Bostwick, J. III, Bried, J.T., Mackay, G., Landry, J. and Benton, J. (1995) TRAM flap breast reconstruction after radiation treatment. Annals of Surgery, 221, 756-764. http://dx.doi.org/10.1097/00000658-199506000-00014

[7] Denham, J.W. and Hauer-Jensen, M. (2002) The radiotherapeutic injury-A complex "wound". Radiotherapy \& Oncology, 63, 129-145. http://dx.doi.org/10.1016/S0167-8140(02)00060-9

[8] Devalia, H.L. and Mansfield, L. (2008) Radiotherapy and wound healing. International Wound Journal, 5, 40-44. http://dx.doi.org/10.1111/j.1742-481X.2007.00351.x

[9] Johnson L.B., Adawi D., Agren M.S., Jorgensen L.N., Wittgren L., Mattsson S., et al. (2006) Combination of pre-operative radiotherapy and surgery suppresses local accumulation of collagen and TGF- $\beta 1$ in rats. Journal of Surgical Research, 133, 136-142. http://dx.doi.org/10.1016/j.jss.2005.12.012

[10] Blumenberg, M. (2005) Skinomics. Journal of Investigative Dermatology, 124, viii-viix. http://dx.doi.org/10.1111/j.0022-202X.2004.23639.x

[11] Menard, C., Johann, D., Lowenthal, M., Muanza, T., Sproull, M., Ross, S., et al. (2006) Discovering clinical biomarkers of ionizing radiation exposure with serum proteomic analysis. Cancer Research, 66, 1844-1850. http://dx.doi.org/10.1158/0008-5472.CAN-05-3466

[12] Bernstein, E.F., Harisiadis, L., Salomon, G., Norton, J., Sollberg, S., Uitto, J., et al. (1991) Transforming growth factor- $\beta$ improves healing of radiation-impaired wounds. Journal of Investigative Dermatology, 97, 430-434. http://dx.doi.org/10.1111/1523-1747.ep12481258

[13] Schultze-Mosgau, S., Wehrhan, F., Amann, K., Radespiel-Troger, M., Rodel, F. and Grabenbauer, G.G. (2003) In Vivo TGF- $\beta 3$ expression during wound healing in irradiated tissue. An experimental study. Strahlentherapie und Onkologie, 179, 410-416.

[14] Jorgensen, L.N. (2003) Collagen deposition in the subcutaneous tissue during wound healing in humans: A model evaluation. APMIS. Supplementum, 115, 1-56.

[15] Overgaard, M. and Christensen, J.J. (2008) Postoperative radiotherapy in DBCG during 30 years. Techniques, indications and clinical radiobiological experience. Acta Oncologica, 47, 639-653. http://dx.doi.org/10.1080/02841860802078085

[16] Mandal, N., Lewis, G.P., Fisher, S.K., Heegaard, S., Prause, J.U., la, C.M., et al. (2011) Protein changes in the retina following experimental retinal detachment in rabbits. Molecular Vision, 17, 2634-2648.

[17] Backovic, A., Huang, H.L., Del, F.B., Piza, H., Huber, L.A. and Wick, G. (2007) Identification and dynamics of proteins adhering to the surface of medical silicones in vivo and in vitro. Journal of Proteome Research, 6, 376-381.

http://dx.doi.org/10.1021/pr0603755

[18] Li, D.Q., Wang, L., Fei, F., Hou, Y.F., Luo, J.M., Zeng, R., et al. (2006) Identification of breast cancer metastasis-associated proteins in an isogenic tumor metastasis model using two-dimensional gel electrophoresis and liquid chromatography-ion trap-mass spectrometry. Proteomics, 6, 3352-3368. http://dx.doi.org/10.1002/pmic.200500617

[19] Shoshan-Barmatz, V., Keinan, N. and Zaid, H. (2008) Uncovering the role of VDAC in the regulation of cell life and death. Journal of Bioenergetics and Biomembranes, 40, 183-191. http://dx.doi.org/10.1007/s10863-008-9147-9

[20] Voehringer, D.W., Hirschberg, D.L., Xiao, J., Lu, Q., Roederer, M., Lock, C.B., et al. (2000) Gene microarray identi- fication of redox and mitochondrial elements that control resistance or sensitivity to apoptosis. Proceedings of the National Academy of Science of the United States of America, Vol. 97, No. 6, 2000, pp. 2680-2685. http://dx.doi.org/10.1073/pnas.97.6.2680

[21] Ebrini, I., Agnello, D., Miller, I., Villa, P., Fratelli, M., Ghezzi, P., et al. (2000) Proteins of rat serum V: Adjuvant arthritis and its modulation by nonsteroidal anti-inflammatory drugs. Electrophoresis, 21, 2170-2179. http://dx.doi.org/10.1002/1522-2683(20000601)21:11<21 70::AID-ELPS2170>3.0.CO;2-1 